\title{
Combustion analysis of a light duty diesel engine using oxygen-enriched and humidified combustion air
}

\author{
Carlo Pirola ${ }^{1}$, Carlo A. Rinaldini ${ }^{2, *}$, Federico Galli ${ }^{1}$, Flavio Manenti ${ }^{3}$, Massimo Milani ${ }^{4}$, \\ and Luca Montorsi ${ }^{4}$ \\ ${ }^{1}$ Università degli Studi di Milano, Dipartimento di Chimica, Milano, Italy \\ ${ }^{2}$ Università di Modena e Reggio Emilia, Dipartimento Ingegneria "Enzo Ferrari”, Modena, Italy \\ ${ }^{3}$ Politecnico di Milano, Dipartimento di Chimica, Materiali e Ingegneria Chimica "Giulio Natta", \\ Milano, Italy \\ ${ }^{4}$ Università di Modena e Reggio Emilia, Dipartimento di Scienze e Metodi per l'Ingegneria, \\ Reggio Emilia, Italy
}

\begin{abstract}
The present work presents the results of 3D CFD combustion simulations of a current production 4-cylinder turbocharged Diesel engine using oxygen-enriched and humidified combustion air. Enriched Air (EA) is supposed to be produced by desorption from water, exploiting the different Henry constants of $\mathrm{N}_{2}$ and $\mathrm{O}_{2}$. Simulation results show that EA permits to increase the engine thermal efficiency (up to 10\%) and drastically reduces soot emissions but increases in-cylinder peak pressure and $\mathrm{NO}_{\mathrm{x}}$ emissions. Combustion air humidification helps to reduce $\mathrm{NO}_{\mathrm{x}}$ increment, without losing the advantage in terms of thermal efficiency and in soot reduction, even if $\mathrm{NO}_{\mathrm{x}}$ emissions cannot be reported to the base case values.
\end{abstract}

\section{Introduction}

Dry air is composed in volume by about $78 \%$ of nitrogen and about $21 \%$ of oxygen with little amount of other gasses, mainly argon. It is the gas mixture used as oxidizing agent in diesel engines. Oxygen enriched air (EA) is a gas mixture with similar composition but with a higher content of oxygen, in the range $22-35 \%$. The use of this mixture in industrial processes is well known, in particular for oxidation reactions or as market products, for example in scuba tanks or for health treatments .

In industrial chemical plants, enriched air is now produced by mixing a stream of pure oxygen with a stream of air [1]. Pure oxygen is currently produced by two different processes, i.e. the air cryogenic separation [2] and the membrane separation [3]. The energy demand for the oxygen production, and consequently for the achievement of enriched air production, is intensive for both these technologies. Moreover, from a process point of

\footnotetext{
* Corresponding author: carloalberto.rinaldini@unimore.it
} 
view, the implementation of oxygen enrichment needs investments for a suitable oxygen supply system, with a control unit for the oxygen injector, in order to guarantee safe and reliable operation procedures.

The present paper reports the study of a new technology for the production of the mixture of enriched air by simple water degassing from water. Moreover, the possible application of EA in Diesel engines, with particular interest for ship application where the availability of water is actually unlimited, will be considered and discussed. The main aim of the work is to evaluate this potential application and then to test it in real conditions.

EA can be produced by desorption from water previously equilibrated with atmospheric air. In fact, due to the higher oxygen solubility in water compared to the nitrogen one, since the Henry constants of this two gases are different [4], the relative composition of $\mathrm{N}_{2}$ and $\mathrm{O}_{2}$ in water is different respect atmospheric air. In fact, depending on the temperature and pressure of the system, oxygen dissolves in water $22-35 \%$ more respect nitrogen .

This new production technology can be limited by the little amount of oxygen and nitrogen solubilized in water and consequently the high quantity of water required for the combustion reaction in the engine. It is possible to overcome this important limitation by adding a pressurized tank for the equilibration of atmospheric air and water before the degassing process. Water and air can be put into contact at high pressure and then the exiting water from the equilibration tank, with high amount of dissolved gas, can be degassed decreasing the pressure. It will be possible to degas water equilibrated with air at room pressure, or under different pressures depending on the on the amount of EA required in the process. Moreover, in order to optimize the water use, this same liquid after its degassing can be further recycled getting it in contact with new atmospheric air.

This new technology for enriched air production was already studied by theoretical considerations and experimental runs [5]. Preliminary process simulations and cost-analysis have been performed with positive feedbacks. [6]. The same technology has been checked from an environmental point of view and the eco-economical prospective, applying the life cycle assessment methodology (LCA), was discussed [7].

The use of enriched air in Diesel combustion engines is well known to be beneficial [8, 9]: EA promoted combustion is considered as one of the most interesting technologies to improve the performance in diesel engines and to simultaneously reduce pollution. The most important advantage, using EA as oxidizer, concerns the decrease in fuel consumption and soot emissions. The application of EA in internal combustion engines has intuitively a tremendous potential: it is obvious that considering the number of engines in the world, also a very little advantage can lead to very important results. The application of EA to internal combustion engines can be proposed for both road vehicles (in this case a water vessel should be added) or, most promising, for ship engines for which the availability of water is actually endless. The authors already explored the potential of EA in Diesel engines [10], analysing, by means of 3D Computational Fluid Dynamics simulations, the effects of EA on the performance and exhaust emissions of a high-speed direct-injection Diesel engine. The simulations revealed that EA permits to increase engine thermal efficiency (up to $8 \%$ ), thanks to a faster and more complete combustion, and drastically reduces soot emissions. The drawbacks of the technology are the increase of in-cylinder peak pressure and the rise of $\mathrm{NO}_{\mathrm{x}}$ emissions. In [10], it has been also found that the increase of in-cylinder peak pressure can be definitely eliminated slightly retarding the injection profile, without losing the advantage in terms of thermal efficiency and in soot reduction, while, the increase of $\mathrm{NO}_{\mathrm{x}}$ emissions does not seem to be easily limited modifying injection timing. The present paper explores, again by means of 3D-CFD simulations, the effectiveness of another technology able to reduce $\mathrm{NO}_{\mathrm{x}}$ emissions: the humidification of combustion air [11]. This technology is a well-known technic for $\mathrm{NO}_{\mathrm{x}}$ reduction in internal 
combustion engine $[12,13]$, but, in the case of EA produced by water degassing, there is a further advantage: EA after degassing phase has a very high water content (relative humidity is close to $100 \%$ ) and then a water injection system is not needed. In the paper, combustion air humidification is applied to the engine in order to reduce the negative effect of enriched air on $\mathrm{NO}_{\mathrm{x}}$ emissions and results are compared with the ones obtained delaying the injection profile.

\section{Enriched air production}

When water is in equilibrium with atmospheric air, it contains different amount of dissolved $\mathrm{O}_{2}$ and $\mathrm{N}_{2}$ depending on the temperature and pressure. In order to increase the amount of oxygen and nitrogen in the water, a pressurized tank in which water and air are put in contact can be proposed. The exiting water, with a high amount of dissolved gas, due to the pressure action, can be then degassed at lower pressure and EA consequently produced. The scheme and the optimization of this continuous plant were already presented and discussed [14], after the experimental validation of the theoretical principles [6]. The amount of water present in the enriched air can be calculated by simulation of the same plant, based on the thermodynamics previously validated. We simulated the proposed flowsheet with the software PRO/II by AVEVA. UNIQUAC was selected as thermodynamic model and the oxygen and nitrogen Henry's coefficient was used, according to Manenti and Pirola [5]. The optimal configuration of the EA production plant is based [6] on a pressurized saturation tank at 30 bar and a degassing tank at 1 bar. Both these are at room temperature to achieve the lowest price for EA. The concentration of water in the enriched air so produced results 0.0419 as molar fraction, i.e. moles of water respect the total number of moles. It is possible to investigate the influence of different experimental parameters on water concentration. The water concentration in the enriched air stream is mainly influenced by temperature and pressure of the degassing tank, as reported in Fig. 1 and Fig. 2, respectively.

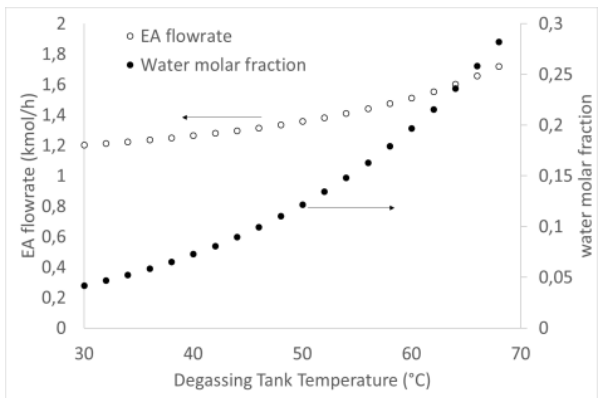

Fig. 1. EA flowrate and water molar fraction vs. degassing tank temperature. Water flowrate in the saturation tank: $5000 \mathrm{~kg} / \mathrm{h}$; air flowrate in the saturation tank: $30 \mathrm{~m}^{3} / \mathrm{h}$.

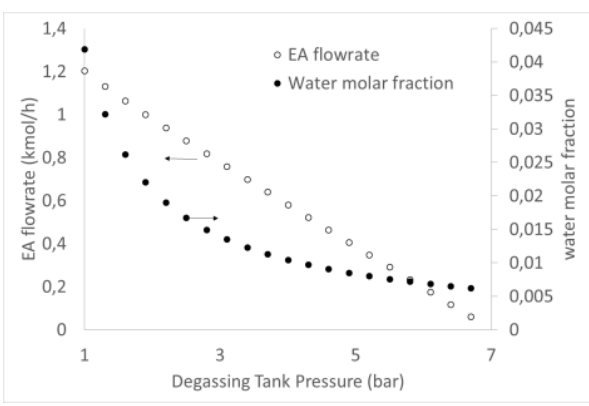

Fig. 2. EA flowrate and water molar fraction vs. degassing tank pressure. Water flowrate in the saturation tank: $5000 \mathrm{~kg} / \mathrm{h}$; air flowrate in the saturation tank: $30 \mathrm{~m}^{3} / \mathrm{h}$.

As shown in the Figures, it is possible to change the water content in the exiting stream of enriched air by using different temperature and pressure in the degassing tank. Water content in fact is dependent from its vapor pressure and then increases for higher temperature and lower pressure. The change of operative parameters obviously influences the EA flowrate too. An increase of temperature increases the gas release, as shown in Fig. 
2, while an increase of the pressure decreases EA production rate. The concentration of oxygen in only little influenced by $\mathrm{T}$ and $\mathrm{P}$ in the considered range.

\section{Engine simulation}

\subsection{The reference engine}

The engine used for the study is a current production turbocharged Diesel engine manufactured by FCA. It has four cylinders, disposed in-line, with a total displacement of $1247 \mathrm{cc}$ and four valves per cylinder. It is equipped with a high-pressure common-rail fuel-injection system and four six-holed electro-injectors. The main features of the engine are listed in Table 1.

Table 1. Main engine parameters.

\begin{tabular}{|c|c|c|c|}
\hline Total displacement & $1247 \mathrm{cc}$ & Number of valves & 4 per cyl \\
\hline Bore x stroke & $69.6 \times 82.0 \mathrm{~mm}$ & Intake valve closing & $33.0^{\circ}$ ABDC \\
\hline Connecting rod & $131.3 \mathrm{~mm}$ & Exhaust valve opening & $67.6^{\circ}$ BBDC \\
\hline Compression ratio & $17.6: 1$ & Injector hole diameter & $0.121 \mathrm{~mm}$ \\
\hline
\end{tabular}

\subsection{The 3D-CFD code}

In this study, a customized version of the KIVA-3V code has been used [15]. The code solves the conservation equations for evaporating fuel sprays, coupled with the 3-Dimensional Computational Fluid Dynamics (3D-CFD) of compressible, multi-component, reactive gases in an engine cylinder with arbitrarily-shaped piston geometry. The sub-models implemented into the customized version of the KIVA $3 \mathrm{~V}$ code are listed in Table 2 . These sub-models were previously implemented by the authors in the framework of the KIVA-3V codes and they are fully described in [16-18]. Moreover, the customized KIVA-3V code has been already applied by authors to the analysis of some current production Diesel engines and the results of calculations was found in very good agreement with experiments, as reported in [18-20].

Table 2. Main models used for 3D-CFD engine modelling.

\begin{tabular}{|c|c|}
\hline Turbulence model & RNG k- $\varepsilon$ model \\
\hline Breakup model & Hybrid KH-RT model \\
\hline Evaporation model & Single component, KIVA-3V \\
\hline Combustion & PaSR coupled with chemical kinetics \\
\hline Fuel composition & Diesel Oil Surrogate Model \\
\hline
\end{tabular}

\subsection{The engine numerical model}

Before application in EA combustion analysis, a 3D model of the engine has been built and validated by comparison with a set of available experimental data in terms of engine performance, indicated quantities (in-cylinder pressure traces, Rate of Heat), and pollutant emissions. Details of the engine model and its validation through comparison with experiments are fully reported in $[10,18]$, thus, in the present paper, only a brief description of the model is reported. The computational grid for combustion simulations is a $60^{\circ}$ sector grid in order to exploit the axial-symmetry of the combustion chamber and consists of 
about 70,000 cells at Top Dead Centre (TDC). Simulations have been carried out at full load, $2000 \mathrm{rpm}$. In this operating point the injection law consists of 2 separate pulses: a pilot injection at about 8 cad BTDC and the main injection at about 4 cad BTDC; the total amount of fuel injected in one stroke is $41.8 \mathrm{mg}$. Initial conditions for combustion simulations, such as pressure, temperature, trapped mass, and charge composition, are obtained from experimental data. As the focus of the present work the combustion phase, only the closed valves part of the cycle is simulated (simulations start at Intake Valve Closing (IVC, $33^{\circ}$ After BDC) and stop at Exhaust Valve Opening (EVO, $68^{\circ}$ Before BDC)); the initial in-cylinder flow field is imposed as an ideal swirl, which intensity is based on previous 3D-CFD simulations. It is important to note that, as far as emissions prediction is concerned, a specific tuning has been required to get a reasonable agreement in terms of absolute values. In particular, for soot analysis, since the oxidation reactions are supposed to be in the gas phase, the predicted concentrations have to be multiplied by one empirical coefficient, determined for matching the experimental values [18].

\section{Results and discussion}

Combustion simulations have been carried out for 2 different EA Oxygen levels $(21 \%$ and $31 \%$ ), 5 Humidity Ratio (HR) and 4 different Start Of Injection (SOI). In details, the relative humidity of combustion air (HR) has been varied from $0 \%$ to $100 \%$ (step $25 \%$ ) and 4 different injection strategies have been investigated, delaying the base injection profile (label " 0 " in the plots) of 2, 4 and 6 crank angle degrees.

The results of the simulation runs were then processed, producing the results reported in figures from 3 to 6 (cycle mean values) and 7 (indicated quantities). These results suggest the following considerations:

- As expected, delaying injection causes a significant decrease of IMEP and, consequentially, a decrease of engine performance and efficiency, but reduces in-cylinder peak pressure;

- Instead, engine performance and efficiency are increased with air enrichment and the improvement seems to be more relevant for late injections (on average $+20 \%$ with 6 cad of delay, $+10 \%$ for base injection); air humidification has a smaller influence of on engine performance and efficiency (IMEP is reduced of $2-3 \%$ from $\mathrm{RH} 0 \%$ to RH 100\%);

- Similarly, in-cylinder peak pressure is significantly increased with EA (+12 bar for base case) but only slightly decreased with air humidification (2-3 bar on average);

- As far as emission are concerned, air oxygen enrichment completely eliminates soot emission but increases $\mathrm{NO}_{\mathrm{x}}$; on the contrary, air humidification and late injections decreases $\mathrm{NO}_{\mathrm{x}}$ and increases soot. On this last point it is however interesting to observe that air humidification seems to have better effects on emissions in comparison with late injections: $\mathrm{NO}_{\mathrm{x}}$ reduction is comparable with the 2 technologies, while soot rise is much more relevant with late injection;

- Referring to base case (oxygen level 21\%) combustion air humidification allows a $\mathrm{NO}_{\mathrm{x}}$ reduction up to $30 \%$ with a slight decrease of IMEP; moreover, soot emissions are just slightly affected by air humiliation up to $\mathrm{RH}=50 \%$ while the $\mathrm{NO}_{\mathrm{x}}$ reduction reaches $20 \%$.

Finally, in order to assess the benefit of combustion air humidification coupled with oxygen air enrichment, the results of 3 different operating points are compared:

- B0 $\left(21 \% \mathrm{O}_{2}, \mathrm{RH} 0 \%\right.$, injection delay 0 cad $)$

- H1 $\left(31 \% \mathrm{O}_{2}, \mathrm{RH} 100 \%\right.$, injection delay 2 cad)

- D2 $\left(31 \% \mathrm{O}_{2}, \mathrm{RH} 0 \%\right.$, injection delay 4 cad $)$ 
Figure 8 reports simulation results for the selected operating points while Figure 9 shows oxygen and temperature distribution on the computational grid symmetry plane during combustion process. It can be observed that soot is almost nullified in the 2 points operating with EA (H1 and D1) while NOx emissions are increased for both of them. One of the causes of $\mathrm{NO}_{\mathrm{x}}$ rise can be found looking at Figure 9 where the increment of combustion temperature with EA is clearly visible. Comparing points $\mathrm{H} 1$ and D2 it can concluded that the best results can be obtained with a combination of combustion air humidification and injection delay: $\mathrm{H} 1$ results in soot and NOx emissions slightly lower than D2, approximatively the same in-cylinder peak pressure of B0 and an IMEP that is 5\% higher than base case.
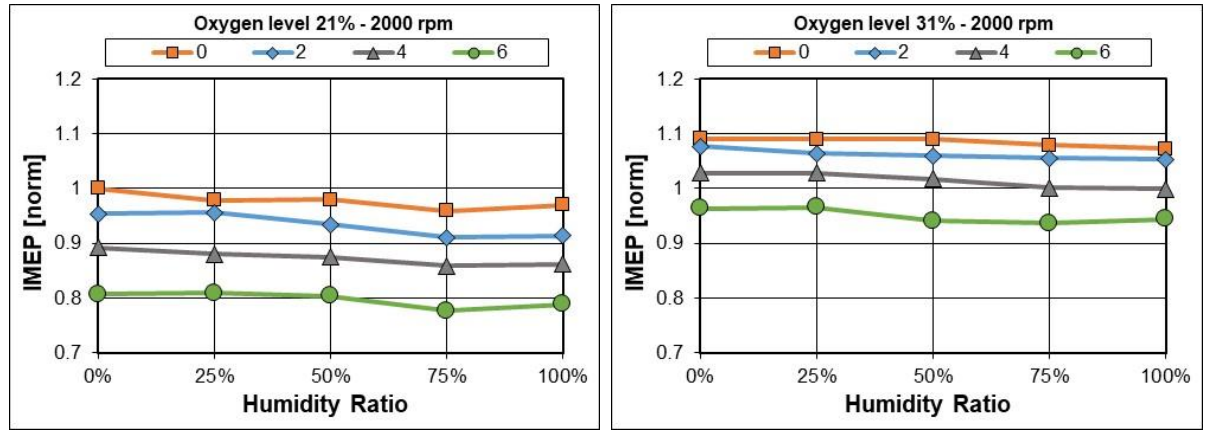

Fig. 3. Gross Indicated Mean Effective Pressure (calculated between IVC and EVO) normalized with reference to the baseline ( $21 \%$ vol. oxygen, $\mathrm{RH} 0 \%$, original injection profile) for (left) base air ( $21 \%$ vol. oxygen) and (right) enriched air (31\% vol. oxygen).
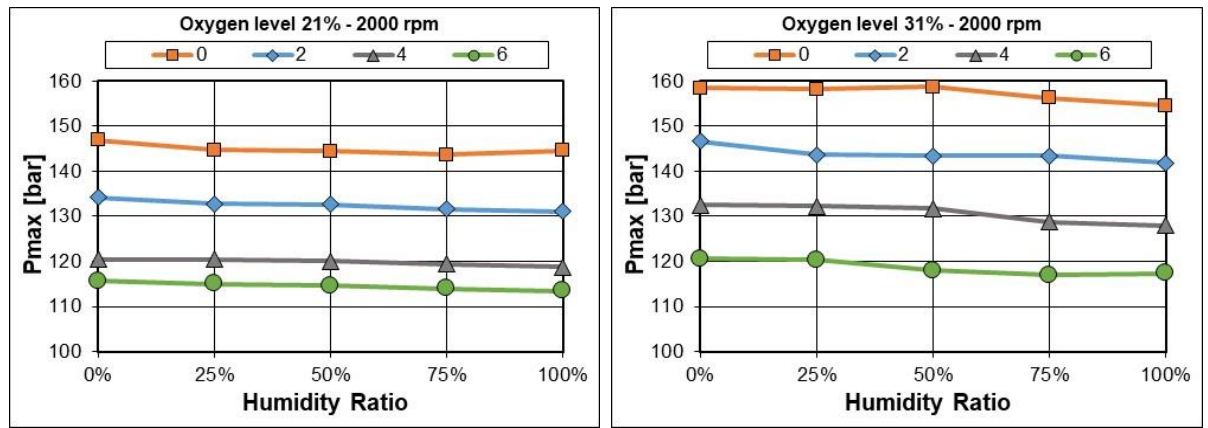

Fig. 4. Max in-cylinder pressure for (left) base air (21\% vol. oxygen) and (right) enriched air (31\% vol. oxygen).
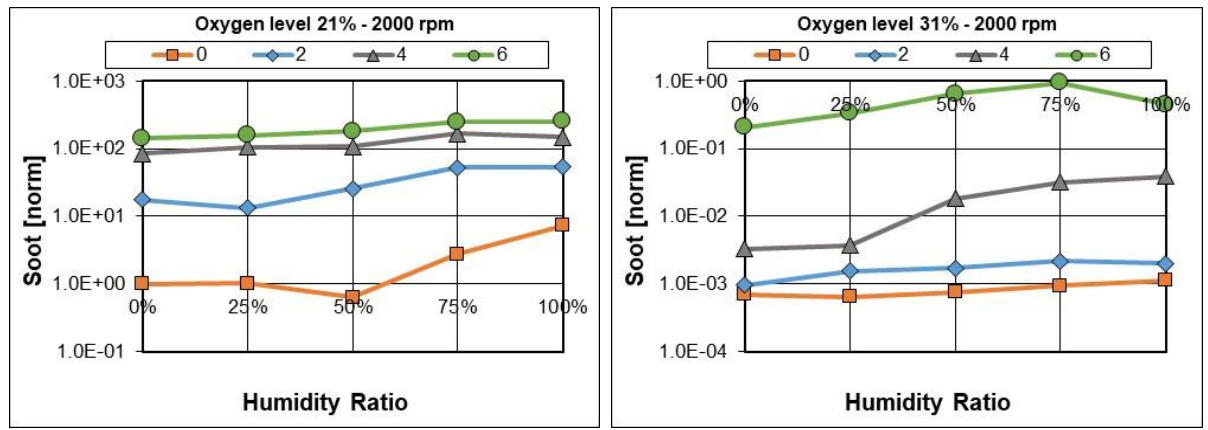
Fig. 5. Soot emissions normalized with reference to the baseline ( $21 \%$ vol. oxygen, RH $0 \%$, original injection profile) for (left) base air ( $21 \%$ vol. oxygen) and (right) enriched air (31\% vol. oxygen).
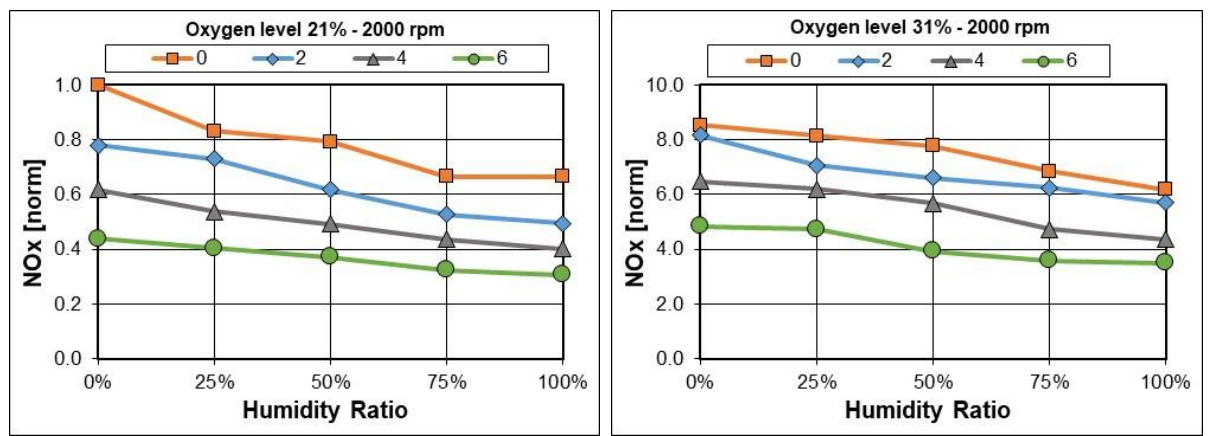

Fig. 6. $\mathrm{NO}_{\mathrm{x}}$ emissions normalized with reference to the baseline ( $21 \%$ vol. oxygen, $\mathrm{RH} 0 \%$, original injection profile) for (left) base air ( $21 \%$ vol. oxygen) and (right) enriched air (31\% vol. oxygen).

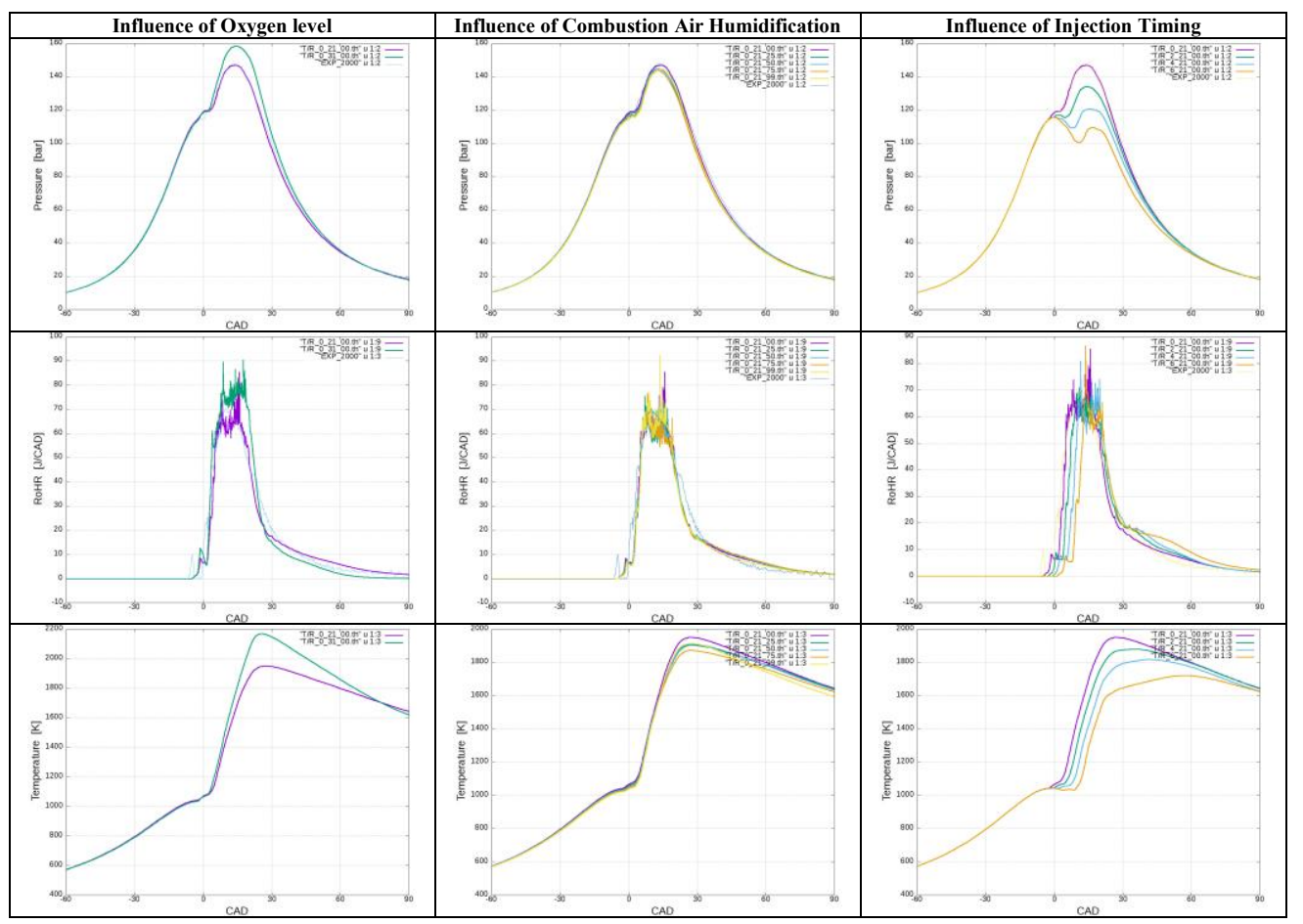

Fig. 7. Effect of enriched air (first column), air humidification (second column) and injection timing (third column) on in-cylinder pressure (first row), Rate of Heat Release (second row) and temperature (third row). 


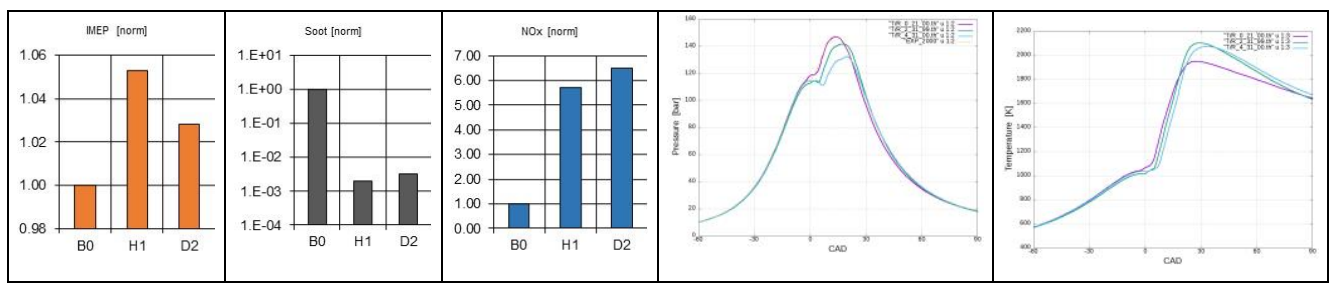

Fig. 8. Comparison between B0 (red line in chart), H1 (green line in chart) and D2 (blue line in chart) in terms of Gross IMEP, soot and NOx emissions, in-cylinder pressure and temperature.

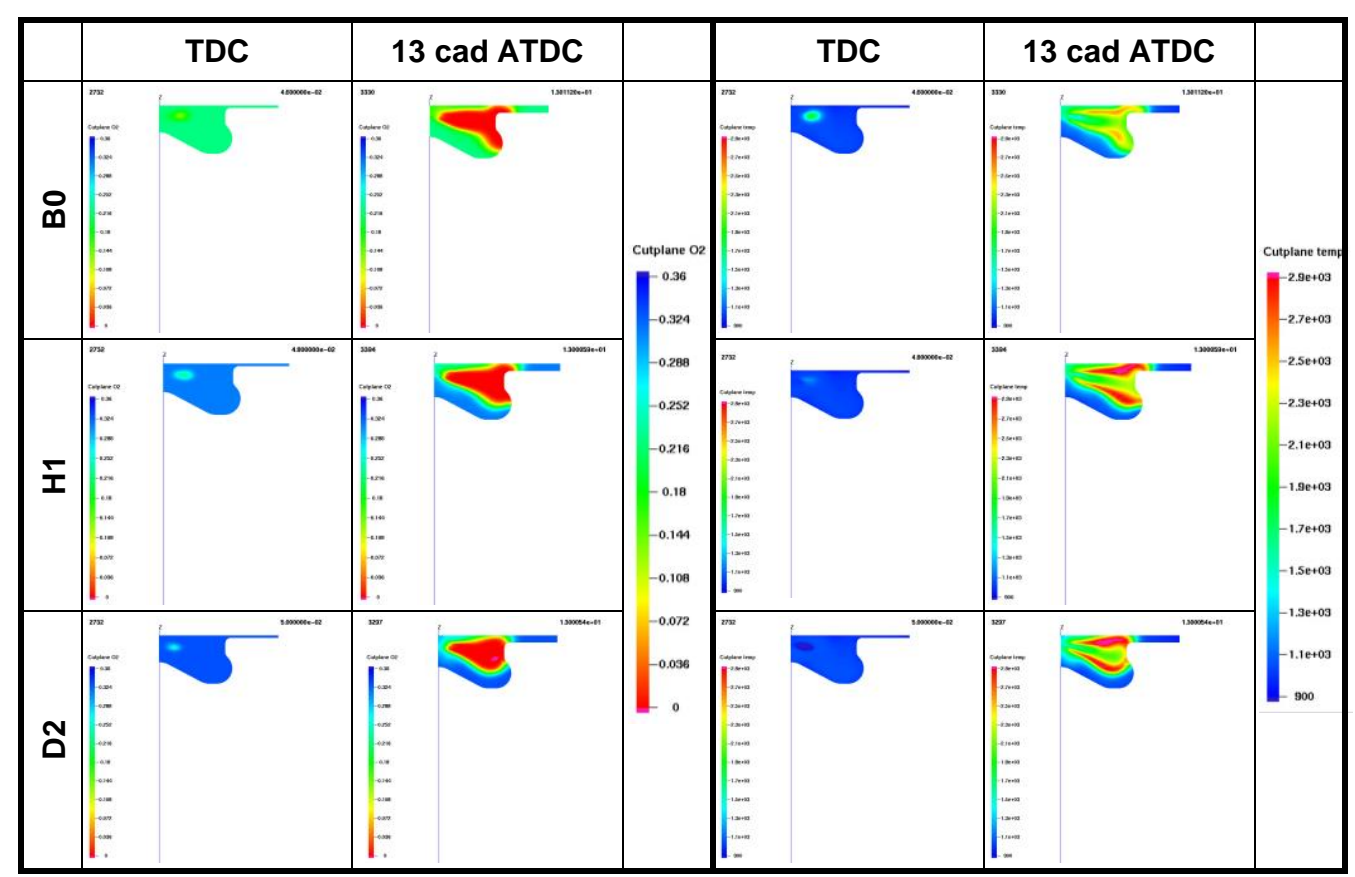

Fig. 9. Oxygen and temperature distribution on a plane passing by the injector axis, for 3 different operating point.

\section{Conclusion}


The goal of this work is to explore, by means of 3D CFD simulations focused on the combustion process, the potential on Diesel engines of oxygen Enriched Air coupled with combustion air humidification. Simulations are carried out on a previously validated through experiments model of a current production 4-cylinder turbocharged Diesel engine.

The simulation results confirm that EA permits to increase engine thermal efficiency (up to $10 \%$ ) and drastically reduces soot emissions but increases in-cylinder peak pressure and $\mathrm{NO}_{\mathrm{x}}$ emissions. Combustion air humidification helps to reduce $\mathrm{NO}_{\mathrm{x}}$ increment, without losing the advantage in terms of thermal efficiency and in soot reduction, even if $\mathrm{NO}_{\mathrm{x}}$ emissions cannot be reported to the base case values. Finally, the best results $(+5 \%$ thermal efficiency, elimination of soot, limited increment of $\mathrm{NO}_{\mathrm{x}}$, same peak pressure of base case) are obtained using EA (oxygen level 31\%) and a combination of combustion air humidification (Humidity Ratio 100\%) and injection postponing (2 cad of delay).

The work was partially financed by the project "Enriched Air POWERed Chemical Plants and Combustion Engines: EAPOWER" in the call "Azione A, Piano sostegno alla ricerca - anno 2018" by Dipartimento di Chimica, Università degli Studi di Milano.

\section{References}

1. H. J. Reinhardt, H. D Obermeyer, B Schreiner, S. Wolf, Oxygen Enrichment for intensification of air oxidations reactions (ISBN 978-3-00-049008-8, 2015)

2. B. Belasissaoui, Y. Le Moullec, H. Hagi, E. Favre, Energy Procedia 63, 497-503 (2014)

3. P. Bernardo, E. Drioli, G. Golemme, Ind. Eng. Chem. Res. 48, 4638-4663 (2009)

4. D. W. Green, R. H. Perry, Perry's Chemical Engineers 'Handbook ( ${ }^{\text {th }}$ Ed, McGrawHill, 2007)

5. F. Manenti, C. Pirola, Chem. Eng. and Processing 79, 40-47 (2014)

6. F. Galli, A. Comazzi, D. Previtali, F. Manenti, G. Bozzano, C. L. Bianchi, C. Pirola, Comput. Chem. Eng. 102, 11-16 (2017)

7. F. Galli, C. Pirola, D. Previtali, F. Manenti, C. L. Bianchi, J. Clean. Prod. 171, 147-152 (2018)

8. P. Baskar, A. Senthilkumar, Eng. Sci. and Technol. An International J. 19, 438-443 (2016)

9. K. Cacua, A. Amell, F. Cadavid, Biomass and Bioenergy 45, 159-167 (2012)

10. F. Manenti, M. Milani, L. Montorsi, F. Paltrinieri, C. Pirola, C. A. Rinaldini, Performance and Exhaust Emissions Analysis of a Diesel Engine Using OxygenEnriched Air (No. 2018-01-1785, SAE Technical Paper, 2018)

11. C. Zhao, K. Wang, S. Huang, Numerical Investigation on Effects of Oxygen-Enriched Air and Intake Air Humidification on Combustion and Emission Characteristics of Marine Diesel Engine (No. 2018-01-1788, SAE Technical Paper, 2018)

12. H. K. Park, S. H. Ghal, H. C. Park, S. W. Choi, S. H. Kim, A Study on NO Reduction of Marine 4-Stroke Diesel Engine Using Charge Air Humidification (No. 2011-240172, SAE Technical Paper, 2011)

13. Y. Lan, R. Zizhong, Diesel Engine, 2 (2007)

14. F. Galli, D. Previtali, G. Bozzano, C. L. Bianchi, F. Manenti, C. Pirola, Journal of Environmental Management 217, 621-628 (2018) 
15. A. A. Amsden, KIVA-3V: A Block-structured KIVA Program for Engines with Vertical or Canted Valves (LA-13313-MS, July 1997)

16. J. Gustavsson, V. I. Golovitchev, SAE Paper 2003-01-1848 (2003)

17. V. I. Golovitchev, N. Nordin, R. Jarnicki, J. Chomiak, SAE Paper 2000-01-1891 (2000)

18. V. I. Golovitchev, L. Montorsi, C. A. Rinaldini, A. Rosetti, ASME Paper ICEF 20061506 (2006)

19. E. Mattarelli, C. Rinaldini, M. Wilksch, SAE Int. J. Engines 4, 2, 2338-2360 (2011)

20. C. A. Rinaldini, E. Mattarelli, V. I. Golovitchev, Applied Energy 112, 102-119 (2013) 